\title{
Prevalence and correlates of attention-deficit
}

\section{hyperactivity disorder symptoms in Korean college students}

This article was published in the following Dove Press journal:

Neuropsychiatric Disease and Treatment

23 March 2015

Number of times this article has been viewed

\section{Young-Sook Kwak \\ Young-Eun Jung \\ Moon-Doo Kim}

Department of Psychiatry, School of Medicine, Jeju National University, Jeju, South Korea
Correspondence: Young-Eun Jung; Moon-Doo Kim

Department of Psychiatry, School of Medicine, Jeju National University, 15 Aran 13-gil, Jeju 690-756, South Korea Tel +82 64717 I234

Fax +82647171849

Email jyejye77@daum.net; mdkim66@ jejunu.ac.kr
Background: Attention-deficit hyperactivity disorder (ADHD) persists into adulthood in a high proportion of cases, causing social difficulties and affective problems. We evaluated the prevalence of symptoms of ADHD and the correlates thereof in Korean college students.

Methods: A total of 2,172 college students, stratified to reflect geographical differences, were asked to complete self-report questionnaires on ADHD symptoms, depression, and related factors.

Results: ADHD symptoms were found in $7.6 \%$ of college students. Univariate analysis revealed that younger students had higher rates of ADHD symptoms than did older students. We found significant associations between ADHD symptoms and problematic alcohol use, depression, and lifetime suicidal behavior. Multivariate analysis revealed that ADHD symptoms in adults were significantly associated with depression (odds ratio $[\mathrm{OR}]=4.69 ; 95 \%$ confidence interval $[\mathrm{CI}] 3.23-6.80 ; P<0.001)$ and overweight or obesity $(\mathrm{OR}=1.50 ; 95 \% \mathrm{CI} 1.02-2.22 ; P=0.040)$, after controlling for sex and age.

Conclusion: These results have implications in terms of the mental health interventions required to assess problems such as depression, alcohol use, obesity, and suicidality in young adults with ADHD symptoms.

Keywords: depression, adult ADHD, alcohol problem, obesity

\section{Introduction}

Attention-deficit hyperactivity disorder (ADHD) is characterized by inattentiveness, hyperactivity, impulsivity, or a combination of these features. ${ }^{1}$ ADHD is the most common behavioral disorder in school-aged children (the incidence ranges from $3 \%$ to $7 \%)^{1}$ and is frequently accompanied by serious complications such as conduct disorder and depression. ${ }^{2}$ Previous studies have found that $30 \%-70 \%$ of individuals diagnosed with ADHD in childhood retain full or residual symptoms as adults. ${ }^{3,4}$ ADHD symptoms in adults are serious risk factors for comorbid psychiatric disorders such as substance use, conduct disorder, and affective disorders, and are significantly correlated with poor socioeconomic outcomes and functional impairment. ${ }^{5-8}$ These poor functional outcomes underscore the importance of the identification and treatment of adults with ADHD. In addition, the diagnosis of ADHD in adults is complicated by several issues (age of symptom onset, symptoms pervasiveness persistence).

Despite the growing literature on adult ADHD, relatively little is known about the prevalence of ADHD symptoms among adults and the correlates thereof in the general Asian population. Given the lack of epidemiological data specific to college students, we conducted a cross-sectional study to investigate the prevalence and correlates of ADHD symptoms among Korean college students. Our study focused on the 
associations of ADHD symptoms with depression, suicidal behaviors, and alcohol use problems.

\section{Materials and methods Participants}

To ensure that geographical differences within the Korean population were accurately reflected, our study sample was selected using stratified cluster sampling based on the regional distributions of college students aged 18 years or older, and we selected 12 universities for inclusion based on 2005 Korean population census conducted by community registry offices. From an initially selected 2,790 college students, a total of 2,210 (79.2\%) participated in the study. We excluded 38 subjects because their responses were incomplete; thus, 2,172 subjects were included in the final analysis. The study was approved by our institutional review board. The subjects were fully informed of the study objectives and methods, and informed consent was obtained from all subjects prior to participation in the study.

A total of 25 research assistants including psychiatric nurses, social workers, and medical students were recruited from across the country. All research assistants were familiar with psychiatric epidemiological surveys. They participated in a 50-minute session to administer the ADHD surveys and fully understood the goals of the study. They screened participants for eligibility, explained the purpose of the study to the subjects, and obtained informed consent. And they were available to answer questions of clarification.

\section{Assessment}

We used a self-report questionnaire to obtain sociodemographic and health-related characteristics including age, sex, academic year, family structure, parental education level, subjective socioeconomic status (SES), school records, family history of psychiatric disorders, previous psychiatric history including childhood ADHD, smoking status, and sleep disturbance. Body mass index (BMI), defined as weight (kg)/square of height $\left(\mathrm{m}^{2}\right)$, was calculated based on self-reported weight and height, and subjects with BMIs $\geq 25$ were classified as overweight or obese. ${ }^{9}$ We used the Alcohol Use Disorder Identification Test (AUDIT) to assess the severity of alcohol use problems. AUDIT consists of ten questions on alcohol consumption, drinking behavior, adverse reactions, and alcohol-related problems during the last year. We defined problematic alcohol use as an AUDIT score $\geq 12 .{ }^{10}$

The Adult ADHD Self-Report Scale-Version 1.1 (ASRSv1.1) Screener is used to screen adults with ADHD. ASRSv1.1 Screener is a subgroup of the symptoms checklist of the 18-question World Health Organization ASRS, which evaluates the frequency of all 18 Diagnostic and Statistical Manual of Mental Disorders, Text Revision, 4th edition, Criterion A symptoms of ADHD. ${ }^{11}$ Each item explores how often a particular symptom of ADHD has occurred over the past 6 months, rated on a 5-point scale, with the response options never (0), rarely (1), sometimes (2), often (3), and very often (4). In our study, the presence of ADHD symptoms in adults was represented by scores of 14 and above. ${ }^{11,12}$

We used the Center for Epidemiologic StudiesDepression Scale (CES-D) to measure depressive symptoms. The CES-D consists of 20 items rated on a 4-point scale from 0 (rarely or none of the time) to 3 (most or all of the time). ${ }^{13}$ A score $\geq 21$ indicates depression according to a previous validation study in the general Korean population. ${ }^{14}$ Lifetime suicidal behavior was assessed using the question, "Have you ever thought seriously about committing suicide or planned a suicide attempt or attempted suicide?"

\section{Data analysis}

Pearson's chi-square test and independent $t$-tests were used to evaluate the relationships between independent and dependent variables. A correlation analysis was performed to evaluate univariate associations between independent variables and ADHD symptoms in adults. Factors potentially associated with ADHD symptoms in adults identified via univariate analysis were next entered simultaneously into a logistic regression model to assess independence. Odds ratios (ORs) and 95\% confidence intervals (CIs) were derived via logistic regression analyses. The Statistical Package for the Social Sciences version 18 (SPSS Inc., Chicago, IL, USA) was used to conduct all statistical tests. $P$-values $<0.05$ (twotailed tests) were deemed statistically significant.

\section{Results}

Of the 2,172 subjects, 1,125 (51.8\%) were male and 1,047 $(48.2 \%)$ female; $87.6 \%$ were between the ages of 18 and 24 years, and the majority $(71.1 \%)$ were of middle SES. A total of 57 (2.6\%) subjects had previous psychiatric histories, and $109(5.0 \%)$ family histories of psychiatric disorders.

We found that $7.6 \%$ of subjects had ADHD symptoms. Moreover, such symptoms were highest among subjects 18-20 years of age, and who had below-average grades. A previous psychiatric history $(P=0.017)$, overweight or obesity $(P<0.001)$, and problematic alcohol use $(P=0.006)$ were significantly related to adult ADHD symptoms. Sex, family structure, self-reported SES, and parental factors were not associated with ADHD symptoms (Table 1). 
Table I Comparisons of characteristics among subjects with and without ADHD symptoms in Korean college students

\begin{tabular}{|c|c|c|c|}
\hline & $\begin{array}{l}\text { Non-ADHD symptoms group } \\
(n=2,008)\end{array}$ & $\begin{array}{l}\text { ADHD symptoms group } \\
(n=164)\end{array}$ & $P$ \\
\hline Age, years & & & $<0.001$ \\
\hline$\leq 20$ & $\mathrm{I}, 12 \mathrm{I}(56.9 \%)$ & 115 (72.3\%) & \\
\hline $21-24$ & $592(30.1 \%)$ & $37(23.3 \%)$ & \\
\hline$\geq 25$ & 257 (I3.0\%) & $7(4.4 \%)$ & \\
\hline Sex & & & 0.632 \\
\hline Male & $\mathrm{I}, 043$ (5I.9\%) & $82(50.0 \%)$ & \\
\hline Female & 965 (48.1\%) & $82(50.0 \%)$ & \\
\hline Family structure & & & 0.366 \\
\hline Living with family & I,3II (65.5\%) & II 4 (69.9\%) & \\
\hline Living alone & 677 (33.8\%) & $47(28.8 \%)$ & \\
\hline Others & $15(0.7 \%)$ & $2(1.2 \%)$ & \\
\hline Parental marital status & & & 0.312 \\
\hline Married & I,7I 3 (85.7\%) & I 35 (83.9\%) & \\
\hline Divorced/separated & $195(9.8 \%)$ & $21(13.0 \%)$ & \\
\hline Widowed & $90(4.5 \%)$ & $5(3.1 \%)$ & \\
\hline Paternal education & & & 0.620 \\
\hline$>12 y$ & $953(50.4 \%)$ & 74 (48.4\%) & \\
\hline$\leq 12 y$ & 936 (49.6\%) & 79 (51.6\%) & \\
\hline Maternal education & & & 0.622 \\
\hline$>12 y$ & $620(32.7 \%)$ & 52 (34.7\%) & \\
\hline$\leq 12 y$ & $1,276(67.3 \%)$ & 98 (65.3\%) & \\
\hline Self-reported SES & & & 0.155 \\
\hline High & 245 (I2.3\%) & $18(\mid 1.0 \%)$ & \\
\hline Middle & I,435 (72.0\%) & $110(67.5 \%)$ & \\
\hline Low & $313(15.7 \%)$ & $35(21.5 \%)$ & \\
\hline School records & & & $<0.001$ \\
\hline Above average & $526(26.5 \%)$ & 47 (29.2\%) & \\
\hline Average & I, I 88 (59.8\%) & $74(46.0 \%)$ & \\
\hline Below average & $272(13.7 \%)$ & $40(24.8 \%)$ & \\
\hline Previous psychiatric history & $48(2.4 \%)$ & $9(5.5 \%)$ & 0.017 \\
\hline Family history of psychiatric disorders & $101(5.0 \%)$ & $8(4.9 \%)$ & 0.941 \\
\hline \multicolumn{4}{|l|}{ Health related conditions } \\
\hline Overweight or obesity & $377(18.8 \%)$ & 49 (30.2\%) & $<0.001$ \\
\hline Sleep disturbances & I, I39 (57.1\%) & $94(58.4 \%)$ & 0.750 \\
\hline Current smoking & $40 \mathrm{I}(20.0 \%)$ & $34(20.7 \%)$ & 0.779 \\
\hline Problematic alcohol use & $320(16.0 \%)$ & $40(24.4 \%)$ & 0.006 \\
\hline
\end{tabular}

Notes: The Adult ADHD Self-Report Scale-Version I.I Screener cutoff point to identify the presence of ADHD symptoms was a score $\geq \mid$ 4; Values are presented as number (\%); Statistical significance is designated by bold type.

Abbreviations: ADHD, attention-deficit hyperactivity disorder; SES, socioeconomic status.

A total of $288(13.3 \%)$ college students had positive CES-D scores, suggesting the presence of depression. Univariate analysis revealed a significant association between depression and ADHD symptoms $(P<0.001)$. The lifetime prevalence of suicidal behavior (suicidal ideation, plan, and attempt) was significantly related to adult ADHD symptoms ( $P=0.046$; Table 2).

Table 3 shows multivariate associations between the independent factors and ADHD symptoms. After adjustment for age and sex, adult ADHD symptoms were significantly associated with depression (OR $=4.69$; 95\% CI 3.23-6.80; $P<0.001)$ and being overweight or obese ( $\mathrm{OR}=1.50 ; 95 \%$ CI 1.02-2.22; $P=0.040$ ).

\section{Discussion}

We found ADHD symptoms in 7.6\% of the Korean college students of our sample. Younger participants (18-20 years of age) had higher prevalence of ADHD symptoms than did older students, and sex was not a risk factor for ADHD symptoms. The prevalence of ADHD symptoms in our sample was higher than the range $(1.0 \%-5.2 \%)$ previously reported for adults aged $\geq 18$ years. ${ }^{5,15-19} \mathrm{~A}$ recent meta-analysis found that the pooled prevalence of adult ADHD was $2.5 \%$ and that the proportion of participants with ADHD decreased with age in the general population. ${ }^{20}$ Recently, Park et al ${ }^{21}$ reported that the prevalence of ADHD symptoms was $1.1 \%$ in Korean adults $18-59$ years of age, and that ADHD symptoms 
Table 2 Comparisons of depression and lifetime suicide behaviors among subjects with and without ADHD symptoms in Korean college students

\begin{tabular}{lll}
\hline & $\begin{array}{l}\text { Non-ADHD symptom group } \\
(\mathbf{n}=\mathbf{2 , 0 0 8 )}\end{array}$ & $\begin{array}{l}\text { ADHD symptoms group } \\
(\mathbf{n}=\mathbf{1 6 4})\end{array}$ \\
\hline $\begin{array}{l}\text { Depression } \\
\text { Yes }\end{array}$ & $221(11.6 \%)$ & $67(42.1 \%)$ \\
$\quad$ No & $1,68 I(88.4 \%)$ & $92(57.9 \%)$ \\
Lifetime suicidal behaviors & $361(18.3 \%)$ & \\
$\quad$ Yes & $1,609(81.7 \%)$ & $40(24.7 \%)$ \\
No & $122(75.3 \%)$ \\
\hline
\end{tabular}

Notes: The Adult ADHD Self-Report Scale-Version I.I Screener cutoff point to identify the presence of ADHD symptoms was a score $\geq 14$; Values are presented as number (\%); Statistical significance is designated by bold type.

Abbreviation: ADHD, attention-deficit hyperactivity disorder.

were most prevalent in young adulthood. The cited authors suggested that the lower prevalence of ADHD symptoms in Korean adults compared to Western countries reflected ethnic/cultural differences. Comparatively few data on the prevalence of ADHD symptoms among college students is available. Previous studies estimated that $3 \%-7 \%$ of college students met the criteria for $\mathrm{ADHD} ; ;^{22-24}$ this is a higher percentage than in the general adult population. However, our results cannot be compared directly to those of previous studies because of differences in the instruments and diagnostic criteria used to assess ADHD. Such methodological differences may explain the discrepancies between our study and those of previous investigators.

Adult ADHD is associated with several psychiatric comorbidities such as depression, anxiety disorder, alcohol and/or substance abuse, bipolar disorder, and a variety of behavioral disorders. ${ }^{16}$ Our finding of a significant association between ADHD symptoms and depression in college students is consistent with previous reports. ${ }^{16}$ Depression in individuals with ADHD may reflect various adjustment difficulties attributable to the cumulative effects of ADHD-related impairments and negative environmental circumstances. ${ }^{25,26}$ However, genetic factors may contribute to the increased risk of depression among individuals with ADHD. Family studies have shown that ADHD and depression share genetic risk factors. ${ }^{27}$ Our finding of an association between suicidal behavior and ADHD symptoms is consistent with previous reports in adolescents with ADHD. ${ }^{28,29}$ ADHD symptoms increase the risk of suicide by intensifying the severity of comorbid conditions such as depression. Furthermore, impulsivity and aggression, common ADHD traits, are recognized as predisposing factors for suicide. ${ }^{28} \mathrm{We}$ found that problematic alcohol use was significantly associated with adult ADHD symptoms in college students. The findings of previous studies suggest that patients with substance use disorders and comorbid ADHD tended to engage in substance abuse at a younger age and experimented more freely than did those without ADHD. ${ }^{30,31}$ Moreover, comorbid ADHD and a variety of psychiatric disorders (depression, bipolar disorder, anxiety disorder, and personality disorder) may

Table 3 Factors associated with ADHD symptoms in Korean college students

\begin{tabular}{|c|c|c|}
\hline \multirow[t]{2}{*}{ Variables } & \multicolumn{2}{|c|}{ Non-ADHD versus ADHD symptoms group } \\
\hline & OR $(95 \% \mathrm{Cl})$ & $\mathbf{P}$ \\
\hline \multicolumn{3}{|c|}{ School records (ref: above average) } \\
\hline Average & $0.71(0.47-1.07)$ & 0.100 \\
\hline Below average & $1.51(0.93-2.43)$ & 0.094 \\
\hline \multicolumn{3}{|c|}{ Depression (ref: no) } \\
\hline Yes & $4.69(3.23-6.80)$ & $<0.001$ \\
\hline \multicolumn{3}{|c|}{ Previous psychiatric history (ref: no) } \\
\hline Yes & $\mathrm{I} .42(0.63-3.20)$ & 0.392 \\
\hline \multicolumn{3}{|c|}{ Problematic alcohol use (ref: no) } \\
\hline Yes & $1.33(0.88-2.03)$ & 0.182 \\
\hline \multicolumn{3}{|c|}{ Overweight or obesity (ref: no) } \\
\hline Yes & $1.50(1.02-2.22)$ & 0.040 \\
\hline
\end{tabular}

Notes: The Adult ADHD Self-Report Scale-Version I.I Screener cutoff point to identify the presence of ADHD symptoms was a score $\geq 14$; The odds ratio (OR) were calculated using binary logistic regression analysis and adjusted for sex and age; Statistical significance is designated by bold type.

Abbreviations: ADHD, attention-deficit hyperactivity disorder; $\mathrm{Cl}$, confidence interval; ref, reference. 
increase the risk of developing an addiction. ${ }^{32}$ Our finding that ADHD symptoms in adults were associated with being overweight or obese is consistent with previous reports. . $^{32,33}$ Previous studies have shown that ADHD increased the risk of overweight or obesity. ${ }^{33,34}$ Behavioral disinhibition is a symptom of ADHD that affects executive function, motivation, and self-regulation of affect. The inability to control impulses may have implications in terms of weight regulation, which requires significant behavioral inhibition, and trigger reactive binge eating in response to negative emotions and environmental cues. ${ }^{33}$

Our study had several limitations. We used self-reported data to assess ADHD symptoms, and had no information on ADHD from childhood, whereas structured clinical interviews would have provided more accurate data on participant symptoms. Furthermore, depression and problematic alcohol use were assessed using self-reported data. Selfreporting measures may be associated with underreporting or underestimation of symptoms. And, we did not evaluate highly comorbid conditions with ADHD such as bipolar disorder, anxiety disorder, and personality disorder. Finally, the cross-sectional nature of the study does not allow us to draw conclusions on causal relationships between ADHD symptoms and related factors such as depression, problematic alcohol use, and obesity. Prospective research is needed to further the understanding of ADHD symptoms and comorbid conditions in college students.

\section{Conclusion}

This is the first epidemiological study to estimate the prevalence of ADHD symptoms among Korean college students. Our findings suggest that identifying individuals at high risk for ADHD who may benefit from comprehensive clinical assessment is important; treatment may mitigate a variety of negative outcomes prevalent in college students and other young adults, such as depression, suicidality, substance use disorder, and obesity.

\section{Acknowledgment}

This work was supported by a research grant from Jeju National University in 2011.

\section{Disclosure}

The authors report no conflicts of interest in this work.

\section{References}

1. American Psychiatric Association. Diagnostic and Statistical Manual of Mental Disorders, Text Revision. 4th ed. Washington, DC: American Psychiatric Association; 2000.
2. Ghanizadeh A, Mohammadi MR, Moini R. Comorbidity of psychiatric disorders and parental psychiatric disorders in a sample of Iranian children with ADHD. J Atten Disord. 2008;12(2):149-155.

3. Barkley RA, Fischer M, Smallish L, Fletcher K. The persistence of attention-deficit/hyperactivity disorder into young adulthood as a function of reporting source and definition of disorder. J Abnorm Psychol. 2002;111(2):279-289.

4. Biederman J, Faraone S, Milberger S, et al. A prospective 4-year follow-up study of attention-deficit hyperactivity and related disorders. Arch Gen Psychiatry. 1996;53(5):437-446.

5. Wilens TE, Faraone SV, Biederman J. Attention-deficit/hyperactivity disorder in adults. JAMA. 2004;292(5):619-623.

6. Kooij JJ, Buitelaar JK, van den Oord EJ, Furer JW, Rijnders CA, Hodiamont PP. Internal and external validity of attention-deficit hyperactivity disorder in a population-based sample of adults. Psychol Med. 2005;35(6):817-827.

7. Kessler RC, Adler L, Ames M, et al. The prevalence and effects of adult attention deficit/hyperactivity disorder on work performance in a nationally representative sample of workers. J Occup Environ Med. 2005;47(6):565-572.

8. Biederman J, Faraone SV, Spencer TJ, Mick E, Monuteaux MC, Aleardi M. Functional impairments in adults with self-reports of diagnosed ADHD: a controlled study of 1001 adults in the community. J Clin Psychiatry. 2006;67(4):524-540.

9. Kanazawa M, Yoshiike N, Osaka T, Numba Y, Zimmet P, Inoue S Criteria and classification of obesity in Japan and Asia-Oceania. World Rev Nutr Diet. 2005;94:1-12.

10. Saunders JB, Aasland OG, Babor TF, de la Fuente JR, Grant M. Development of the Alcohol Use Disorders Identification Test (AUDIT): WHO Collaborative Project on Early Detection of Persons with Harmful Alcohol Consumption - II. Addiction. 1993;88(6):791-804.

11. Kessler RC, Adler L, Ames M, et al. The World Health Organization Adult ADHD Self-Report Scale (ASRS): a short screening scale for use in the general population. Psychol Med. 2005;35(2):245-256.

12. Kessler RC, Adler LA, Gruber MJ, Sarawate CA, Spencer T, Van Brunt DL. Validity of the World Health Organization Adult ADHD Self-Report Scale (ASRS) Screener in a representative sample of health plan members. Int J Methods Psychiatr Res. 2007;16(2):52-65.

13. Radloff LS. The use of the Center for Epidemiologic Studies Depression Scale in adolescents and young adults. J Youth Adolesc. 1991; 20(2):149-166.

14. Cho MJ, Kim KH. Use of the Center for Epidemiologic Studies Depression (CES-D) Scale in Korea. J Nerv Ment Dis. 1998;186(5):304-310.

15. Fayyad J, De Graaf R, Kessler R, et al. Cross-national prevalence and correlates of adult attention-deficit hyperactivity disorder. $\mathrm{Br} \mathrm{J}$ Psychiatry. 2007;190:402-409.

16. Kessler RC, Adler L, Barkley R, et al. The prevalence and correlates of adult ADHD in the United States: results from the National Comorbidity Survey Replication. Am J Psychiatry. 2006;163(4):716-723.

17. de Graaf R, Kessler RC, Fayyad J, et al. The prevalence and effects of adult attention-deficit/hyperactivity disorder (ADHD) on the performance of workers: results from the WHO World Mental Health Survey Initiative. Occup Environ Med. 2008;65(12):835-842.

18. Faraone SV, Biederman J. What is the prevalence of adult ADHD? Results of a population screen of 966 adults. J Atten Disord. 2005;9(2):384-391.

19. Murphy K, Barkley RA. Prevalence of DSM-IV symptoms of ADHD in adult licensed drivers: implication for clinical diagnosis. $J$ Atten Disord. 1996;1:147-161.

20. Simon V, Czobor P, Bálint S, Mészáros A, Bitter I. Prevalence and correlates of adult attention-deficit hyperactivity disorder: meta-analysis. Br J Psychiatry. 2009;194(3):204-211.

21. Park S, Cho MJ, Chang SM, et al. Prevalence, correlates, and comorbidities of adult ADHD symptoms in Korea: results of the Korean epidemiologic catchment area study. Psychiatry Res. 2011;186(2-3):378-383.

22. DuPaul GJ, Schaughency EA, Weyandt LL, et al. Self-report of ADHD symptoms in university students: cross-gender and cross-national prevalence. J Learn Disabil. 2001;34(4):370-379. 
23. Heiligenstein E, Conyers LM, Berns AR, Miller MA, Smith MA. Preliminary normative data on DSM-IV attention deficit hyperactivity disorder in college students. J Am Coll Health. 1998;46(4):185-188.

24. Weyandt LL, Linterman I, Rice JA. Reported prevalence of attentional difficulties in a general sample of college students. J Psychopathol Behav Assess. 1995;17:293-304.

25. Ostrander R, Crystal DS, August G. Attention deficit-hyperactivity disorder, depression, and self- and other-assessments of social competence: a developmental study. J Abnorm Child Psychol. 2006;34(6):773-787.

26. Herman KC, Lambert SF, Ialongo NS, Ostrander R. Academic pathways between attention problems and depressive symptoms among urban African American children. J Abnorm Child Psychol. 2007;35(2): 265-274.

27. Faraone SV, Biederman J. Do attention deficit hyperactivity disorder and major depression share familial risk factors? J Nerv Ment Dis. 1997; 185(9):533-541.

28. James A, Lai FH, Dahl C. Attention deficit hyperactivity disorder and suicide: a review of possible associations. Acta Psychiatr Scand. 2004;110(6):408-415.
29. Shaffer D, Gould MS, Fisher P, et al. Psychiatric diagnosis in child and adolescent suicide. Arch Gen Psychiatry. 1996;53(4):339-348.

30. Biederman J, Wilens TE, Mick E, Faraone SV, Spencer T. Does attention-deficit hyperactivity disorder impact the developmental course of drug and alcohol abuse and dependence? Biol Psychiatry. 1998;44(4): 269-273.

31. Wilens TE, Biederman J, Mick E, Faraone SV, Spencer T. Attention deficit hyperactivity disorder (ADHD) is associated with early onset substance use disorders. J Nerv Ment Dis. 1997;185(8):475-482.

32. Biederman J, Wilens T, Mick E, Milberger S, Spencer TJ, Faraone SV. Psychoactive substance use disorders in adults with attention deficit hyperactivity disorder (ADHD): effects of ADHD and psychiatric comorbidity. Am J Psychiatry. 1995;152(11):1652-1658.

33. Cortese S, Faraone SV, Bernardi S, Wang S, Blanco C. Adult attentiondeficit hyperactivity disorder and obesity: epidemiological study. $\mathrm{Br} J$ Psychiatry. 2013;203(1):24-34.

34. Pagoto SL, Curtin C, Lemon SC, et al. Association between adult attention deficit/hyperactivity disorder and obesity in the US population. Obesity (Silver Spring). 2009;17(3):539-544.

\section{Publish your work in this journal}

Neuropsychiatric Disease and Treatment is an international, peerreviewed journal of clinical therapeutics and pharmacology focusing on concise rapid reporting of clinical or pre-clinical studies on a range of neuropsychiatric and neurological disorders. This journal is indexed on PubMed Central, the 'PsycINFO' database and CAS, and is the official journal of The International Neuropsychiatric Association (INA). The manuscript management system is completely online and includes a very quick and fair peer-review system, which is all easy to use. Visit http://www.dovepress.com/testimonials.php to read real quotes from published authors. 